\title{
Blended Learning: An Innovative Approach
}

\author{
Lalima $^{1, *}$, Kiran Lata Dangwal ${ }^{2}$ \\ ${ }^{1}$ Department of M.Ed, Rama Degree College, Lucknow, Uttar Pradesh, India \\ ${ }^{2}$ Department of Education, University of Lucknow, Lucknow, Uttar Pradesh, India
}

Copyright $\mathrm{O} 2017$ by authors, all rights reserved. Authors agree that this article remains permanently open access under the terms of the Creative Commons Attribution License 4.0 International License

\begin{abstract}
Blended learning is an innovative concept that embraces the advantages of both traditional teaching in the classroom and ICT supported learning including both offline learning and online learning. It has scope for collaborative learning; constructive learning and computer assisted learning (CAI). Blended learning needs rigorous efforts, right attitude, handsome budget and highly motivated teachers and students for its successful implementation. As it incorporates diverse modes so it is complex and organizing it is a difficult task. The present paper discusses the concept of blended learning, its main features and prerequisite of its implementation. Scope of blended learning in Indian educational system is also discussed .The present paper also tries to explain that how blended learning is an approach that needs to be adopted.
\end{abstract}

Keywords Blended Learning, ICT Supported Teaching Learning Process, Traditional Teaching Learning Process, and Computer Assisted Learning, Online Learning

\section{Introduction}

The educational system at present is in a transition stage. To meet the challenges of expansion and for catering individuals need it is trying to adopt new technologies and exploring new paths to reach the goal of quality educational opportunities for all, at the same time due to various factors like deficient budgets, lack of facilities, advantages of face to face interaction, it is not completely ready to leave the traditional modes of knowledge transfer. Even the students are in a state of dual mind. When a group of teacher trainees were inquired about the mode of teaching they will prefer from tradition classroom teaching and ICT supported teaching the students were nearly evenly divided between both the choices.

The traditional mode of teaching in spite of its few shortcomings provides a much needed human touch to the teaching learning process. Personality and behaviour of the teachers directly influences the blooming personality of the students. Only face to face interaction meets the affective objectives along with cognitive and psychomotor. Face to face traditional approach helps in developing a strong value system. Social skills like cooperation, sharing, expression and respecting other's views are more easily developed in traditional mode of teaching. Students learn not only from books, or from teachers teaching inside classroom but also from the co-students, through their peer group interaction, they learn many skills in playground and their small social interactions in canteens, lounge etc. All this is necessary for a proper personality development

As discussed above that traditional approach has its own benefits but it is not free from deficiencies. It has following shortcomings:

- It is failing to meet the individual needs of all the students in the class basically due to improper pupil teacher ratio

- It is not adapting itself to meet the challenge of teaching physically challenges students

- Teachers are not trained for integrated classroom.

- It is not fit to meet the challenges put forward by the irregular students as attendance is must and evaluation system depends on the annual examination. If students fail to take the examination his whole year is a waste, due to rigidity the irregular students are in a way excluded from the main stream of school system.

- Similarly absence of professional counsellors and absence of right attitude of the teachers and dearth of follow up activities in the schools the children who discontinue the school for any reason do not get the chance for entering in the formal educational system again.

- School is not able to reach every child and so education for all is still a far sighted goal

- Children from deprived groups, from the areas that are geographically isolated and medically unfit students are not able to gain benefit from this formal traditional mode of teaching.

- At the same time students have to suffer due to dearth of teachers, their learning has many ambiguities due to inefficient teachers.

- Course are not regularly revised, books are not updated and teachers are not interested in upgrading their 
knowledge and professional skills, the result is that our students are not well prepared to meet the demands of the modern market and professions.

To make their knowledge correlate with the present technological advancement and globalization, to minimize the teaching errors, to improve the quality, to increase students exposure ICT supported teaching learning process is a good option. ICT supported teaching provides new dimension to teaching learning process, introduces students to the wide pool of knowledge and opens before them innumerable opportunities to learn, unlearn and relearn, All types of learners whether in- service, physically challenged all can be benefitted by this mode of teaching. It helps reaching to all students. In the words of Swami Vivekanand "if people cannot reach school schools should reach them", ICT supported learning is exactly doing the same.
Analysis of both the traditional mode of teaching learning process and ICT supported teaching learning process show that both have few merits and demerits, both are catering different needs, demands and expectations from the educational system, so the solution is to provide and design such a system that is based on an integrated approach, a system that incorporates the main features of both traditional approach of teaching and ICT supported teaching. The demand of today is an approach that blends the advantages of both the modes for the student's learning i.e. blended learning.

\section{Blended Learning}

Blended learning can be explained by following figure:

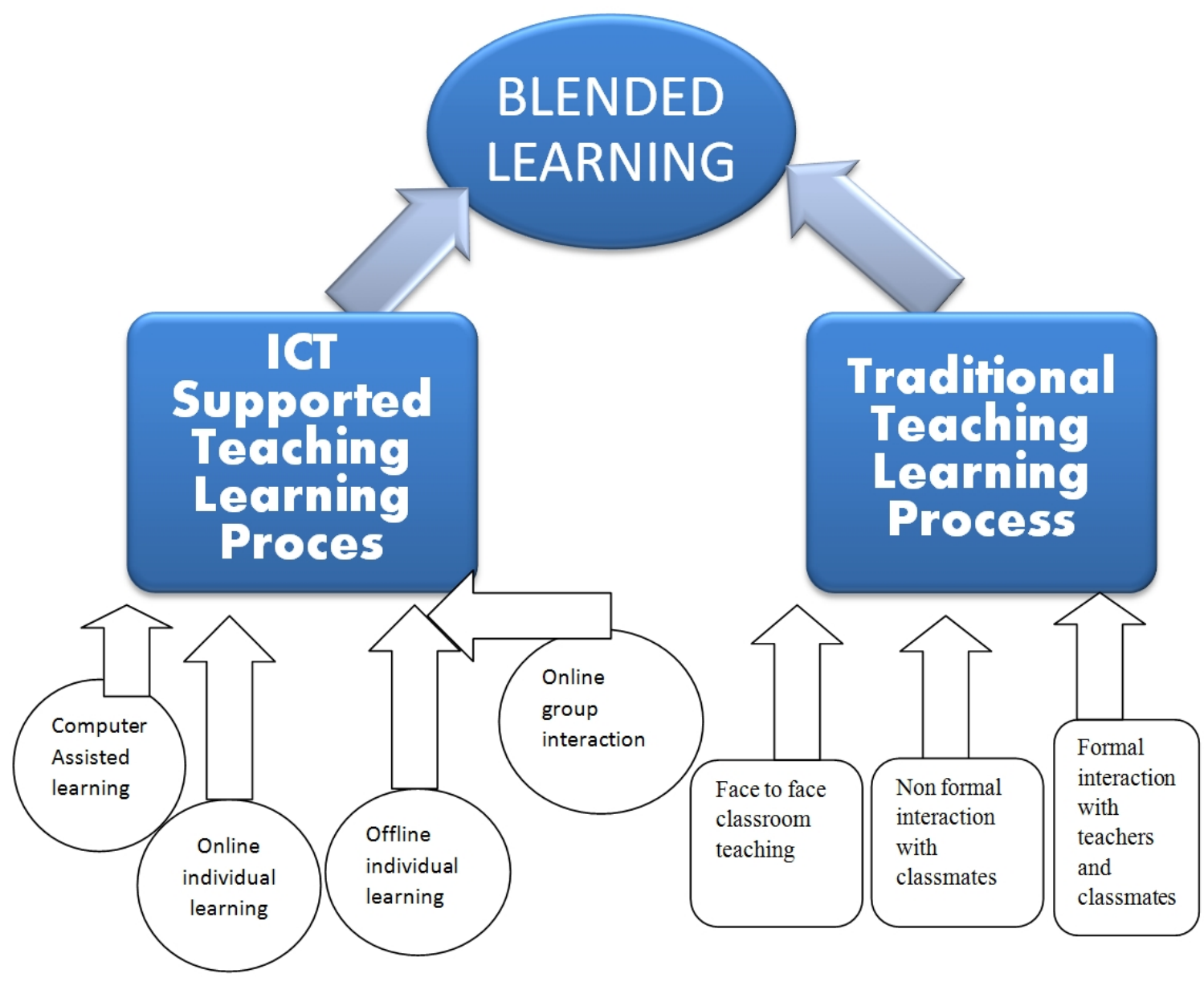


Blended learning is the concept that includes framing teaching learning process that incorporates both face to face teaching and teaching supported by ICT. Blended learning incorporates direct instruction, indirect instruction, collaborative teaching, individualized computer assisted learning. As the figure shows it includes:

a) Face to face teaching- blended learning provides full scope for traditional classroom teaching where students get ample of time to interact with their teachers and thus get influenced by their personality, behaviour and value system. Face to face interaction helps in synchronous communication. Teachers and students both are able to get immediate feedback that in turns is favourable for teaching learning process. Face to face interaction is highly motivating for both the teachers and students and it gives a human touch to the process

b) Student interaction with course content- traditional mode of teaching and the school campus provides student time to interact directly with their course content through printing material and ICT mediated learning provides them indirect interaction with their course content in a versatile and diverse interesting way. The videos provide required realism to the content and sharing on blogs and visiting e-books provide new and updated perspectives to the content.

c) Peer group interaction- inside the school campus students learns by formal means and they also learn informally when they interact with their peer groups. Many needed life skills and social values are practised in non-formal interaction with their peer groups. School campus provides many opportunities for this during playground activities, social exchange during free time

d) Group discussion and exchange of ideas- classroom teaching not only provides students interaction with teachers but well-designed strategies give students to undergo discussions with their class mates on different aspects of the course and exchange ideas. This helps to develop confidence in students, remove their hesitation and develop the skill of communicating effectively and also develop good listening skill.

e) Accessing e-library- this is a part of ICT supported teaching learning in blended learning. In traditional mode students get access to school library that is limited but digital library gives them access to different books related to their topic and on diversified areas. This widens their outlook and enriches their knowledge, this helps in meeting the cognitive objectives.

f) Virtual classroom- this provides student an option to learn anywhere, anytime and from anyone. Students can be a part of a virtual classroom meeting with his co-students and teacher in cyber space irrespective of the geographical boundaries. School can also provide provision for it so that the system gains flexibility and students who cannot attend school regularly can gain advantage from this mode. As well as student can get attach to other experts and enhance his knowledge. With world today turning into a global village, students through this mode will be at par with his counterpart at any other part of the world and will get multicultural experience also.

g) Online assessment- immediate feedback is a key factor in learning as it motivates the learner and is based on principles of readiness. Online assessment helps to make evaluation system more formative, transparent and more fast. It becomes more reliable and objective.

h) e-tuitions- students have different needs. Few of the students don't get benefits from classroom teaching as they continuously require personal guidance and complete attention. Such students may choose the option of e-tuition that is meeting a private tutor and getting personal guidance in cyber space via video conferencing.

i) Accessing and maintaining educational blogsstudents get less opportunity for nurturing their creativity in traditional classrooms because of rigid time table and lot of pressure of class work, assignments and coping with examination stress but educational blogs provide students a platform to show their creativity and can get feedback also. In addition to it, educational blogs are a good platform to discuss topics of importance that are not the part of syllabus like those related to social problems, political issues, and other issues relevant to youths like drugs addiction, delinquency, population education etc.

j) Webinars- webinar is an also a feature of blended learning that is ICT supported format. It means that students participate in seminars in different topics relevant to them via internet connection. All the participants are connected through different software's available like Skype, Google talk etc. and then present their paper and participate in discussions through video conferencing.

k) Viewing expert lectures in YouTube- the blended earning provides student to gain advantage of the experts of the course content they are studying as they can easily watch the different lectures by renowned experts from different fields available on you tubes. In addition to it college can also upload video of lecture by its own teachers so that if student is not able to attend the college he can avail this facility and can gain benefit of the teachers teaching

1) Online learning through videos and audios- various recordings, animated videos are available that explain various concepts very easily and in interesting way. They are based on the principle of realism and connecting with life. So students can get feel of real life while studying and it makes the difficult concepts and phenomenon concrete for the students.

m) Virtual laboratories-it can be used in professional courses where the laboratory work is very crucial and sometimes the cost of establishing a well-furnished laboratories is not feasible and in few cases the experiments are dangerous and it is not safe for students to handle those equipments then in such cases students 
can access virtual laboratories and can learn need skills by working in this virtual laboratory.

All these features when blended in one frame it is called blended learning.

\section{Main Characteristics of Blended Learning}

The main features of blended learning are-

- Students have the option of the two modes- students in blended learning can select either the traditional mode of classroom teaching where they can get personal interaction with teacher and their classmates or they can choose ICT supported teaching learning. This largely depends on the nature of content and objectives being targeted. Sometime course designer or teachers themselves decide on the mode appropriate for topic being dealt with.

- Teachers are well versed with both the modes - it is an important feature of the blended learning that teachers are very dynamic, techno savvy and fully trained to work efficiently in both the formatstraditional classroom format and ICT supported format. They will be well equipped in using traditional methods and other modern technologies

- Students get face to face interaction as well they interact in virtual space- students get ample of time to interact with other students pursuing same course. They can interact with them inside college campus and also in virtual space. Thus their group become very large and has much diversity so the student's knowledge becomes wide and they also develop a feeling of understanding, love and harmony with students of other cultures and countries.

- Students get full experience in using new technology- the present century is the century of ICT. Today the illiterate is not only the one who cannot read and write but a person who is not well versed with modern technologies is also illiterate. Today all professions demand expertise in ICT so blended learning help to make student's ICT experience rich. Students involved in blended learning gain capability to exploit available technologies to the fullest of their benefit

- Students get training in different life skills- life skills are those skills that are needed to lead a happy peaceful and successful life. The major life skills are empathy, decision making capability, love, patience, communication, self-management, critical thinking. The blended learning helps the students to practice these skills. Students get acquainted with few skills like love, empathy, patience in classroom through his teachers, classmates, and few like self-management, decision making, critical thinking, communication through the online experiences.
All round development of personality is targeted. In blended learning the students get full opportunity for all round development of the personality. All the aspects of personality namely- cognitive, physical and emotional are developed through blended learning which is difficult to achieve in traditional mode or ICT approach if followed in isolation. Tradition classroom teaching is helpful in memory level and understanding level of teaching and so help in cognitive domain development and at same time teacher's behaviour, playground experience and social group with classmates develop affective and physical domain at same time online experiences help in reflective level of learning so develop higher faculties of min and social networking sites and other social interactions though internet help in right type of value development.

- Physical development is possible with in school campus- the online learning and ICT supports teaching learning process is often targeted with the blame that it ignores physical development of the students. The blended learning overcomes this limitation. As it included school experience also so student get time for playing, physical work, yoga inside the college campus.

- Students get wide exposure and new perspectives of the course content-due to variety of experience students get wide exposure and their content knowledge is enriched, they get to see various new dimensions of the content gain practical useful knowledge.

- It has a human touch- due to physical prescience of teacher via traditional approach students get that human touch which is very necessary for balanced student's emotional quotient and very necessarily up to secondary level.

- It provides multicultural and multi dimension approach to teaching learning process-blended learning approach provides student opportunity to communicate and share their views and feeling with the students all over the world thus it makes teaching learning process multicultural and variety of experience bring with it the interdisciplinary and multidimensional factor also.

- Makes teaching learning process child centeredblended learning is designed to provide maximum gain to students and thus reach the goal of child centered education.

- Diverse role of teacher- teacher in blended learning is playing different role, traditional role of a teacher in classroom, she acts as motivator, as a resource person, as an organiser, as a developer, when she develops content to be provided through ICT, as a guide on the side. Thus teacher gets freedom from the monotonous traditional roles and she can try her hands in diverse areas that are good for her professional growth also.

- Student constructs knowledge rather than just consuming it. Blended learning also includes constructivism. Students construct their own knowledge 
rather than depending on others to design teaching-learning strategies for them.

\section{Prerequisite of Blended Learning}

Implementing blended teaching is not an easy task. It requires certain fundamental preparations in all the elements of teaching learning process- teacher, student, content designing, and infrastructure. The following are the basic requirements for implementing a successful blended learning.

1. Well trained teachers- though child centered but teachers are an important pole of blended learning. Teachers should be well acquainted with the concept of blended learning and fully trained and skilled to blend both types of approaches- tradition and technological. They should be trained to develop content in digital form so that it can be available to students online. They should be well versed with internet browsing and internet terminology, should be aware of all the websites that can be useful for the students while learning online. Teacher should know how to utilize blogs, you tube facility, software like Skype, goggle talk and others for video conferencing and social networking sites for educational purposes.

2. Teachers with scientific attitude- it is very important that teachers have scientific attitude. They should have good observation skill, they should be optimistic should have problem solving skills. Scientific attitude will help the teachers to deal positively with failures she will get while working on this innovative concept and will help to analyse the conditions objectively. This right type of scientific temper will automatically filter from teachers to students

3. Teachers with wider outlook and positive approach towards change - as it is must for the success of any innovative idea or method blended learning process also need teachers that have a wider outlook and should be flexible, they should be ready to accept the changes and very innovative and dynamic.

4. Complete facilities like well-furnished computer lab, internet connection, provision for video chatting- it is the compulsory factor of blended learning. Blended learning largely depend on infrastructure, school should not only have good classrooms but should also have a well-furnished compute laboratories with sufficient number of computes to cater to all the students of one class and the internet facility, a Wi-Fi campus if possible.

5. Students have access to internet at their private computers- in addition to school having fully ICT friendly campus students should have basic hardware support to learn online and offline at their residence also. This requires a positive attitude and good investments schemes from the government.

6. Flexibility in the system- The system should be flexible, flexible time table, examinations system all this is very crucial for implementing blended learning.

7. Fully aware and agreed Parents- the parents should be made well aware of this innovative approach to teaching so that they are ready for it and support their wards for the blended learning and can accept that this deviation from traditional teaching is beneficial for their children

8. Formative evaluation and continuous internal assessment- the school authorities and higher educational bodies should be ready to completely implement continuous internal assessment(CAI) and other tools of formative evaluation as summative evaluation is not supported in the blended learning . The provision should be made for online examination for making the system more flexible.

These are few essentials and basic requirements without which the blended learning cannot be executed successfully.

\section{Advantage of Blended Learning}

Blended learning has following advantages-

- As part of learning is done through ICT, online or offline mode so teachers and students get more time in the classroom for creative and cooperative exercise.

- Students gain advantage of online learning and CAI without losing social interaction element and human touch of traditional teaching'

- It provides more scope for communication. Communication cycle is completed in blended learning which is not possible if we follow only traditional approach

- Students become more techno savvy and they gain enhanced digital fluency

- Students have more strengthened professionalism as they develop qualities like self-motivation, self-responsibility, discipline

- It updates course content and so gives new life to established courses

\section{Relevancy of Adapting Blended Learning in India}

Indian education system is suffering from various problems like failing to expand the system to provide provision of free and compulsory education to all children, abating to maintain quality along with increasing the quantity, education curriculum is not able to meet demands of international market and not even able to conserve and propagate Indian value system, teachers are not fully dedicated towards their profession and teacher's inefficiency is adversely influencing the learning of the students. There is an urgent need of some radical steps and major revolutions within to overcome the challenges. Blended learning to some extent will help in solving these problems of Indian 
education system.

- In our country due to large population the formal schools system is not able to provide equal educational opportunities to all, so blended learning will be a good option as it will make the area of educational opportunities wider and education will be able to reach to more children.

- The technological and scientific development continuously demands the education system to match their pace and correlate with them so that students are able to cope up with the fast changing market. Technology and scientific field are most dynamic and changing at great pace incorporating new innovations so the content transmitted to students have to be revised accordingly but in India courses are generally not so frequently revised and updated so if blended learning will be adapted students and teachers can easily update their knowledge and skills

- Dearth of good teachers is also a major issue. Teachers are less in number, still many primary schools are not having appropriate teacher pupil ratio, this problem exist not only in government sector but private institutes are in a similar state. There is another serious issue that teacher working are also not very dedicated towards the profession so blended learning is a good option as online learning can be a substitute of teacher

- Generally problem of indiscipline, irregular attendance and dropouts etc. exist because our traditional mode is not able to cater individual demands of every student and is not making the delivery of this content interesting for the students. Moreover course is not focussed, students are not confident and secure of their future so this unrest and stress leads to the problem of indiscipline but blended learning will be a combo solution to all these problems. As discussed above blended learning provides variety of experiences to the students, make them active and they remain in focus of teaching learning process due to increased involvement and bearing the responsibility of their learning themselves make students more disciplined. And as blended learning is giving students more upgraded and quality education that is from dynamic resource so learning thus becomes more purposeful.

- Still the education for all is a major challenge. Constitution provides the provision of free and compulsory education for all the children up to age 14 but our system is not able to meet this goal also. But if our educational institutes implement blended learning then they can easily increase the enrolment irrespective of geographical boundaries.

- Educated students are also not efficient and skilled to meet the demands of global market so suffer unemployment but as discussed above the blended learning will help students to master all modern techniques and life skills that will help them in leading a successful life
- The education of special children also poses problems but blended learning with its diversity can easily cater to the needs of special children like those who are brilliant can satisfy their thrust of knowledge in blended learning, blind students can easily be educated in blended learning as ICT supported teaching learning process will provide technical support in their learning, similarly physically challenged can also become part of main stream education and get enrolled in good institutes without bothering about the distance as blended learning will help them study online and from home.

- The quality of education largely higher education is also a serious issue. None of our higher education institutes are among the top institutes of the world so to exist in the completion and to enhance quality adopting blended learning will be a good option. When students will get experience of both types of modes their knowledge will enrich. Reaching the experts and content material available online our students will gain advanced skills that will make them strong eligible candidates of good jobs. These exposures will surely overcome the limits in the syllabus designing or methodologies.

- Similarly another problem in our education system is that it is failing to develop in students right value system and love toward Indian culture and tradition as it is adopting itself in modern technologies but blended learning gives equal importance to traditional mode and classroom teaching and thus can give students essence of Indian value system.

\section{Implementation of Blended Learning in Indian Education System}

Implementing blended learning needs a full dedication on the part of educational authorities and managements of educational institutes. It needs a well-planned design that include all from individuals top to bottom of the educational hierarchy. For preparing educational institutes for blended learning we will need to increase educational budgets, it can be done by taking help of NGOs and also coordinating with the industrial and corporate sector. These sectors can be motivated to give their financial inputs for blended learning execution as these sectors will be most benefited if, the output from these educational institutes are more efficiently groomed for the global market. The other very important issue that has to be considered is development of right type of attitudes towards this ground-breaking concept in all those who are concerned with educational system. For changes in attitudes of parents, community, teachers and students awareness programmes, seminars, discussion forums should be organised. These can be utilized to make people aware about the benefits of blended learning so that a right mind set is prepared for its implementation. Mass media can well be 
utilized for this purpose. Teacher training programmes both in-service and pre-service have to be reoriented to prepare teachers for blended learning approach. The finance and efforts that are put in for various projects to meet education for all should be re directed in preparing our primary schools for blended learning as it will cater many problems simultaneously and both finance and efforts are more fruitfully utilized.

To conclude it can be said that blended learning is to some extent is the solution to problems prevailing in our educational system. If implemented in a well-planned, organised way with right type of attitudes it can become the future of our educational system. It is in our own benefit that steps for adapting blended learning are soon initiated.

\section{REFERENCES}

[1] "Blended Learning (Staker / Horn - May 2012)" (PDF). Retrieved 2013-10-24.

[2] "Blended Learning: A Disruptive Innovation". Knewton.

[3] "Plato Rising". Atarimagazines.com. Retrieved 2013-10-24.

[4] Alexander, S., \& McKenzie, J. (1998). An Evaluation of Information Technology Projects for University Learning. Canberra, Australia: Committee for University Teaching and Staff Development and the Department of Employment, Education, Training and Youth Affairs. http://jite.org/documents/Vol5/v5p235-249Heinze156.pdf

[5] Bonk C.J., \& Graham, C.R. (2006). The handbook of blended learning environments: Global perspectives, local designs.

[6] Coach resources (2012-10-11). "in the real world | Coach resources". Khan Academy. Retrieved 2013-10-24.

[7] Collis, B. (2005) ICT for Blended Learning Available at

[8] Creating a Premium Blend? 20 Questions and a Case Study - Learning Solutions article by Gina Ann Orefice

[9] Dangwal Kiran L.: (2004) Computers in Teaching and Learning:Shre Vinod Pustak Manir, Agra

[10] Dangwal Kiran L.: (2013) Computers Shiksha: Vedant Publication: Lucknow

[11] Duzer, J.V. (2002) Instructional Design Tips for Online Learning Available at en.wikipedia.org/wiki/Blended learning

[12] Epic (2009a) White Paper - Blended Learning

[13] Epic (2009b) White Paper - Blended Learning in practice

[14] Friesen, Norm (2012). "Report: Defining Blended Learning"

[15] Garrison, D. R., \& Kanuka, H. (2004). Blended learning: Uncovering its transformative potential in higher education. The Internet and Higher Education, 7, 95-105.

[16] Harel Caperton, Idit. (2012) Learning to Make Games for Impact. The Journal of Media Literacy, 59(1), 28-38.

[17] HEFCE (2003) the costs of alternative modes of delivery.
Available at

http://media.wiley.com/product data/excerpt/67/07879729/0 787972967.pdf

[18] http://tarunagoel.blogspot.com/2010/04/make - it blended.html

[19] http://uupinfo.org/research/working/bradford.pdf

[20] http://web.mit.edu/training/trainers/guide/deliver/train guide - matrix.pdf

[21] http://www.cellbiol.eu/docs/ICT_for_blended_learning_Coll is.pdf

[22] http://www.csuchico.edu/tlp/resources/rubric/instructionalDe signTips.pdf

[23] http://www.hefce.ac.uk/pubs/rdreports/2003/rd14_03/

[24] http://www.learningsolutionsmag.com/articles/279/creating - a - premium - blend - 20 - questions - and - a - case study

[25] http://www.wlecentre.ac.uk/cms/files/occasionalpapers/wle op2.pdf

[26] https://www.coursera.org/course/blendedlearning

[27] Interactive Learning Centers Announces Name Change to EPIC Learning. (1999, March 5). The Free Library. (1999). Retrieved October 18, 2013 from http://www.thefreelibrary.com/Interactive Learning Centers Announces Name Change to EPIC Learning.-a054024665

[28] Jacob, Anna M. (2011). Benefits and Barriers to the Hybridization of Schools. Journal of Education Policy, Planning and Administration, 1(1): 61-82.

[29] Jara, M and Mohamad, F. (2007) Pedagogical templates for e-learning Available at www.wlecentre.ac.uk.

[30] M. Gosper, D. Green, M. McNeill, R.A. Phillips, G. Preston, K. Woo, Final Report: The Impact of Web-Based Lecture Technologies on Current and Future Practices in Learning and Teaching, Australian Learning and Teaching Council, Sydney

(2008)<http://mq.edu.au/ltc/altc/wblt/docs/report/ce6-22 fin al2.pdf $>$.

[31] Make it Blended - Blog Post by Taruna Goel

[32] Martyn, Margie (2003). "The hybrid online model: Good practice." Educause Quarterly: 18-23.

[33] MIT Training Delivery Guide - Delivery Method Matrix by Kate Kibbee and Jeanette Gerzon

[34] Prantosh, K. P., Dipak, C., Kumar, A. (2012). "E Learning: New Age Knowledge Model Delivery through Advance Information Technology and Cloud Computing: An Overview" BRICS International Journal of Educational Research, Vol. 3 No. 1, ISSN-2231-5829, Page-22-25, MM University, Ambala, Haryana, India.

[35] S. Alexander, Flexible Learning in Higher Education, In: Editors-in-Chief: Penelope Peterson, Eva Baker and Barry McGaw, Editor(s)-in-Chief, International Encyclopedia of Education (Third Edition), Elsevier, Oxford, 2010, Pages 441-447, ISBN 9780080448947 http://dx.doi.org/10.1016/B978-0-08-044894-7.00868-X. 
[36] Salmon, G. (2002) E-tivities Oxon, RoutledgeFalmer

[37] Strauss, Valerie (22 September 2012). Three fears about blended learning, The Washington Post

[38] weblearning.psu.edu/blended-learning.../what_is_blended_le arning
[39] www.knewton.com/blended learning

[40] www-07.ibm.com/services/pdf/blended_learning.pd 